\title{
Cardiac Autonomic Modulation by Estrogen in Female Mice Undergoing Ambulatory Monitoring and In Vivo Electrophysiologic Testing
}

\author{
Samir Saba, M.D., Vladimir Shusterman, Ph.D., Irmute Usiene, M.D., \\ and Barry London, M.D., Ph.D. \\ From the Cardiovascular Institute, University of Pittsburgh Medical Center, Pittsburgh, Pennsylvania
}

\begin{abstract}
Introduction: Estrogen is an important modulator of cardiovascular risk, but its mechanism of action is not fully understood. We investigated the effect of ovariectomy and its timing on the cardiac electrophysiology in mice.

Methods: Thirty female mice (age $18.8 \pm 3.1$ weeks) underwent in vivo electrophysiologic testing before and after autonomic blockade. Fifteen mice were ovariectomized prepuberty (PRE) and ten postpuberty (POST), 2 weeks prior to electrophysiologic testing. Five age-matched sham-operated female mice (Control) served as controls. A subset of 13 mice (5 PRE, 3 POST, and 5 Controls) underwent 24-hour ambulatory monitoring.

Results: With ambulatory monitoring, the average (668 \pm 28 vs $769 \pm 52 \mathrm{~b} / \mathrm{min}, \mathrm{P}=0.008$ ) and minimum $(485 \pm 47$ vs $587 \pm 53 \mathrm{~b} / \mathrm{min}, \mathrm{P}=0.02)$ heart rates were significantly slower in the ovariectomized mice (PRE and POST groups) compared to the Control group. At baseline electrophysiologic testing, there were no significant differences among the ovariectomized and intact mice in any of the measured parameters. With autonomic blockade, the Control group had a significantly larger change $(\triangle)$ in the atrioventricular (AV) nodal Wenckebach (AVW) periodicity $(\triangle \mathrm{AVW}=$ $11.3 \pm 2.9$ vs $2.1 \pm 7.3 \mathrm{~ms}, \mathrm{P}=0.05)$ and functional refractory period $(\triangle \mathrm{FRP}=11.3 \pm 2.1 \mathrm{vs}$ $1.25 \pm 6.8 \mathrm{~ms}, \mathrm{P}=0.02)$ compared to the ovariectomized mice. These results were not altered by the time of ovariectomy (PRE vs POST groups).

Conclusion: Our results suggest that estrogen modulates the autonomic inputs into the murine sinus and AV nodes. These findings, if replicated in humans, might underlie the observed clustering of certain arrhythmias around menstruation and explain the higher incidence of arrhythmias in men and postmenopausal women.

A.N.E. $2004 ; 9(2): 142-148$
\end{abstract}

estrogen; cardiac electrophysiology; autonomic; mice

Gender differences in cardiac electrophysiology have been appreciated for many years. ${ }^{1-4}$ For example, compared to men, women have a lower risk of developing Wolf-Parkinson-White Syndrome but they have a higher risk of developing atrioventricular (AV) nodal reentrant tachycardia. ${ }^{3}$ Also, as they age, women compared to men are relatively protected from developing atrial fibrillation., ${ }^{4,5} \mathrm{Gen}$ der differences in certain electrophysiology (EP) parameters, such as the corrected QT interval, have also been described ${ }^{6-8}$ and are associated with a higher susceptibility of women to torsades de pointes, particularly in the presence of drugs that prolong the QT interval. ${ }^{9}$ Paradoxically, the over- all incidence of sudden cardiac death is lower in women than men independent ofcoronary artery disease risk. ${ }^{4}$

Numerous mechanisms have been proposed to explain the gender disparities in arrhythmia susceptibility and cardiac electrophysiology. These have ranged from differences in the expression and function of cardiac ion channels ${ }^{10-13}$ all the way to variations in the activation of the autonomic nervous system. ${ }^{14-18}$ Recently, attention has been focused on the role of estrogen and other gonadal hormones in regulating cardiac EP. ${ }^{19,20}$ For example, the occurrence and inducibility of certain paroxysmal arrhythmias vary during different

Address for reprints: Samir Saba, M.D., Division of Cardiac Electrophysiology, University of Pittsburgh Medical Center, 200 Lothrop Street, B535 PUH, Pittsburgh, PA 15213.Fax:+1-412-647-7979; E-mail: sabas@msx.upmc.edu 
portions of the menstrual cycle. ${ }^{21,22}$ In addition, gonadal hormones can increase the threshold for ischemia/reperfusion-induced ventricular fibrillation. ${ }^{23-25}$ To date, however, the exact mechanisms that underlie hormone-based differences in cardiac electrophysiology have not been established.

We had previously shown that low estrogen states shorten murine AV nodal conduction times and the right ventricular refractory period during in vivo electrophysiologic testing under the effect of type IA antiarrhythmic medications, and that estrogen replacement therapy restores these parameters to their original values. ${ }^{26}$ In this study, we investigated the hypothesis that ovariectomy and its timing influence cardiac electrophysiology in female mice and that this effect is modulated, at least in part, through the autonomic nervous system.

\section{METHODS}

\section{Mice}

The protocol used was approved and monitored by the Division of Laboratory Animal Medicine staff in full compliance with the American Association for the Accreditation of Laboratory Animal Care. A total of 30 females $\mathrm{C} 3 \mathrm{H}$ mice (age $18.8 \pm$ 3.1 weeks) underwent blinded in vivo EP testing before and 10 minutes after intraperitoneal (IP) administration of atropine $(0.5 \mathrm{mg} / \mathrm{kg}, \mathrm{IP})$ and propranolol $(1 \mathrm{mg} / \mathrm{kg}$, IP), for complete autonomic blockade. The mice were anesthetized with injections of avertin $2.5 \%(0.015 \mathrm{~mL} / \mathrm{g}$ body weight, IP).

A subset of 13 mice underwent 24-hour ambulatory monitoring 1 week prior to the EP testing.

The study protocol is detailed in Figure 1. Briefly, the mice were divided into three groups depending on the status and timing of their ovariectomies: 15 mice (PRE group) underwent ovariectomy prepuberty at 2 weeks of age, 10 postpuberty (POST group) at 14 weeks of age, and 5 mice (Control group) underwent a sham operation at 14 weeks of age. Mice from each group underwent 24-hour ambulatory monitoring at 17 weeks of age, 1 week after recovering from the insertion of the implantable transmitters. All mice then underwent in vivo cardiac electrophysiologic testing before and after autonomic blockade at 18 weeks of age.

\section{Ambulatory Monitoring}

Thirteen mice (five from the PRE group, three from the POST group, and five Controls) under-
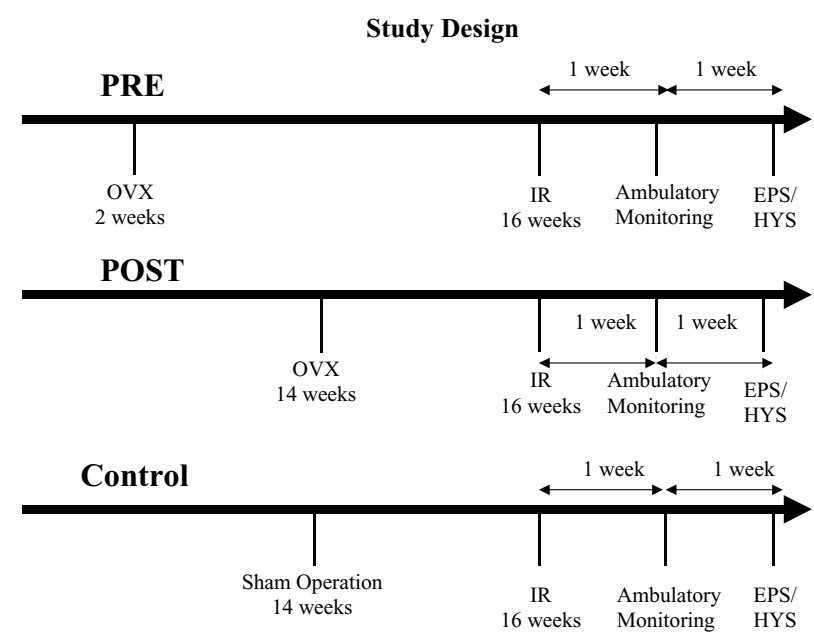

Figure 1. Study design showing the study events for mice in the three study groups. OVX = ovariectomy; $\mathrm{IR}=$ implantable recorder; $\mathrm{EPS}=$ electrophysiologic study; HYS = hysterectomy.

went the insertion of implantable transmitters, as previously described. ${ }^{27}$ Briefly, $3.5 \mathrm{~g}, 1.8 \mathrm{cc}$ wireless transmitters (Data Sciences International, St Paul, MN) were implanted on the backs of the mice. The two leads from each transmitter were tunneled subcutaneously to the right shoulder and the left subcostal areas, respectively, to simulate recordings from a lead II surface electrocardiogram. The procedure was performed under anesthesia with ketamine $(0.033 \mathrm{mg} / \mathrm{g})$ and xylazine $(0.010 \mathrm{mg} / \mathrm{g})$ given intraperitoneally. The mice were allowed to recover from the surgery for about a week prior to being monitored. On the day of monitoring, the mice were placed in their cages over receiver plates connected to a computer (Data Sciences International, St Paul, MN) where the digitized signals were stored for analysis. The acquired signal was sampled at a frequency of $400 \mathrm{~Hz}$ for all animals with an amplitude resolution of $1 \mathrm{mV} / \mathrm{cm}$. The mice were allowed free ambulation in their cages and free access to water and food during the monitoring phase, which lasted 24 hours. All ambulatory monitors were analyzed for heart rate, cardiac cycle intervals, and spontaneous atrial or ventricular arrhythmia occurrence. Cardiac cycle intervals were measured and averaged over three consecutive beats.

\section{In Vivo Electrophysiologic Testing}

As previously described, ${ }^{26,28}$ the mice were housed in cages in a facility with 12-hour light and 
dark cycles, at a temperature of $24^{\circ} \mathrm{C}$ and were fed rodent chow and allowed free access to water. Mice were anesthetized by intraperitoneal administration of avertin $2.5 \%(0.015 \mathrm{ml} / \mathrm{g}$ body weight, IP). A 6-lead electrocardiogram was obtained by placing 24-gauge needles subcutaneously in each limb. A right external jugular vein cutdown was performed and a 2 French octapolar catheter (NuMed Inc., Hopkinton, NY) was advanced to the right ventricular apex, until a bipolar His bundle electrogram could be recorded from the middle electrodes. All surgical procedures were carried out under a surgical microscope (Nikon, model SMZ 1B). After the procedure, the uteri of the mice were excised and weighed.

\section{Electrophysiology Protocol}

As previously described ${ }^{26,28}$ all intracardiac signals were sampled at $2 \mathrm{KHz}$, amplified and filtered at $30-500 \mathrm{~Hz}$. Surface signals were filtered at 0.01$100 \mathrm{~Hz}$ (Labsystem Duo Bard Electrophysiology, Lowell, MA). Baseline cardiac cycle intervals were measured in all the mice including the cycle length RR, PR, QRS, QT, AH, and HV intervals (Fig. 2). The RR interval was measured between two consecutive beats at the beginning of the QRS complex. The PR interval was measured from the beginning
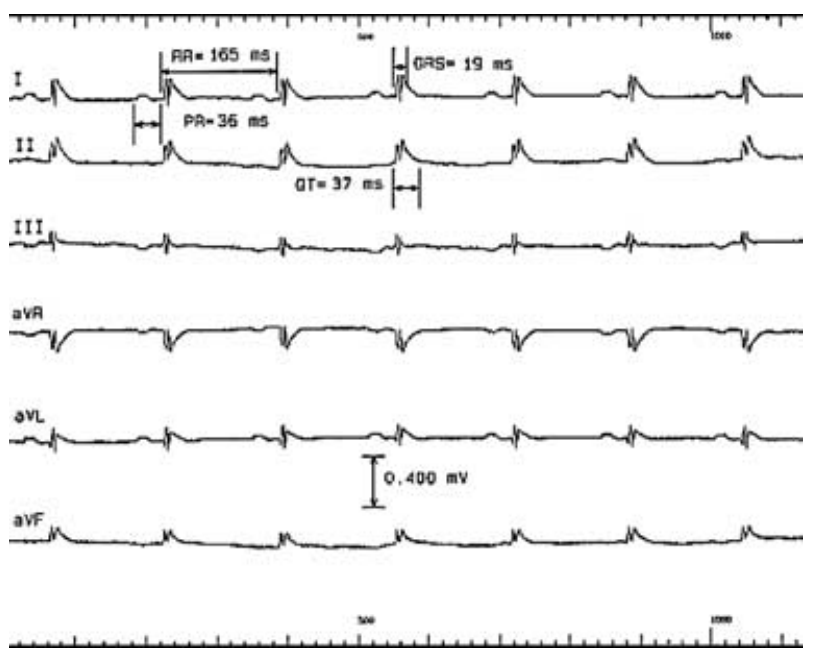

Figure 2. Six-lead surface electrocardiogram from a mouse showing measurements of the cardiac cycle intervals. Note the difficulty in determining the QRS and QT intervals given the fact that in the mouse, unlike in humans, the T wave starts before the QRS deflection returns to the isoelectric line and that the T wave is of low amplitude. of the $\mathrm{P}$ wave to the beginning of the QRS complex. The QRS duration was measured from the beginning to the end of the high frequency sharp signal representing depolarization. Given that the end of the $\mathrm{T}$ wave onset in the mouse takes place before the QRS deflection returns back to the isoelectric line, the end of the QRS component was taken as the point where the down-slope electrical waveform becomes less steep by visual assessment. The QT interval was measured from the beginning of the QRS complex to the point where the $\mathrm{T}$ wave meets the isoelectric line. Given the difficulty in assessing the end of the $\mathrm{T}$ wave on the surface ECG, recordings from all six limb leads were amplified (X 32) and measurements of the QT interval was averaged over three consecutive beats. On the intracardiac recordings, the $\mathrm{AH}$ interval was measured from the beginning of the atrial signal to the beginning of the His deflection, whereas the HV interval was measured from the beginning of the His deflection to the beginning of the QRS complex on the surface ECG. All measurements were done with electronic calipers at a speed of $200 \mathrm{~mm} / \mathrm{s}$. Atrial and ventricular pacing thresholds were then determined and pacing was conducted using $2.0 \mathrm{~ms}$ pulse widths at twice-diastolic threshold (Bloom stimulator, Fisher Imaging Corp., Reading, PA). Sinus node function was evaluated by measuring sinus node recovery time (SNRT) after pacing the right atrium at a cycle length of $100 \mathrm{~ms}$ for 60 seconds, and correcting it for the baseline heart rate (SNRTc $=$ SNRT $-\mathrm{RR})$. Atrioventricular (AV) and VA Wenckebach and 2:1 cycle lengths were determined. Programmed atrial and ventricular stimulation were performed by delivering a premature stimulus after the eighth stimulus in a drive train. Effective refractory periods (ERP) as well as functional refractory periods (FRP) were determined at a cycle length of $100 \mathrm{~ms}$ for both the $\mathrm{AV}$ and VA conduction. Ventricular effective refractory period was also determined at a drive cycle length of $100 \mathrm{~ms}$. Premature atrial and ventricular stimulation curves were constructed and compared between the study groups. Programmed ventricular stimulation, consisting of burst pacing at cycle lengths of $100 \mathrm{~ms}-50 \mathrm{~ms}$ in decrements of $10 \mathrm{~ms}$, and of programmed stimulation with double and triple extrastimuli at a drive cycle length of $100 \mathrm{~ms}$ with a coupling interval greater or equal to $30 \mathrm{~ms}$ was performed. Inducibility was predefined as 10 beats of ventricular tachycardia (VT) after the last pacing stimulus. After the administration of 
atropine $(0.5 \mathrm{mg} / \mathrm{kg}$, IP) and propranolol $(1 \mathrm{mg} / \mathrm{kg}$, IP), repeat measurement of all electrophysiologic parameters was done. Also, repeat atrial and ventricular programmed stimulation was undertaken. Measurements of all the parameters were done by a blinded observer.

\section{Estrogen Levels}

As previously shown in our laboratory, ${ }^{26}$ the weight of the uteri in the mice correlates well with the plasma level of estrogen as measured by radioimmunoassay. For this study, the weight of the uteri was used as a surrogate measure of the plasma estrogen level in mice from all study groups.

\section{Statistical Analysis}

All the measurements are reported as a mean \pm standard deviation. Effects of hormonal manipulation were examined using a one-way ANOVA test. Initial comparisons were made among the three study groups for all ambulatory and invasive parameters. In the absence of any differences between the PRE and POST groups, the analysis was repeated comparing the ovariectomized to the sham-operated mice. A P value less than or equal to 0.05 was considered statistically significant.

\section{RESULTS}

Twenty-four-hour continuous ambulatory monitoring recordings were analyzed. The average heart rate was slower in the PRE group and the POST group compared to the Control mice $1666 \pm 31$ $\mathrm{b} / \mathrm{min}$ and $672 \pm 29 \mathrm{~b} / \mathrm{min}$ compared to $769 \pm 52$ $\mathrm{b} / \mathrm{min}$ respectively, $\mathrm{P}=0.005)$. There were no significant differences between the PRE and POST groups, which were grouped together (OVX group) for the rest of the analysis. The average $(668 \pm 28$ $\mathrm{b} / \mathrm{min}$ vs $769 \pm 52 \mathrm{~b} / \mathrm{min}, \mathrm{P}=0.008)$ and mini$\operatorname{mum}(485 \pm 47 \mathrm{~b} / \mathrm{min}$ vs $587 \pm 53 \mathrm{~b} / \mathrm{min}, \mathrm{P}=0.02)$ heart rates were significantly slower in the ovariectomized mice (PRE and POST groups) compared to the Control group (Fig. 3). There was no evidence of any atrial or ventricular arrhythmias in any of the OVX or Control mice. There were no significant differences between the OVX and Control mice in the mean PR $(34.9 \pm 5.7 \mathrm{~ms}$ vs $31.3 \pm 0.8 \mathrm{~ms}, \mathrm{P}=$ $0.19)$, QRS $(12.8 \pm 1.1 \mathrm{~ms}$ vs $14.3 \pm 1.3 \mathrm{~ms}$, $\mathrm{P}=0.06)$, or QT $(36.2 \pm 2.2 \mathrm{~ms}$ vs $35.9 \pm 2.0 \mathrm{~ms}$, $\mathrm{P}=0.82$ ) intervals.

At baseline in vivo electrophysiologic testing, there were no significant differences among the

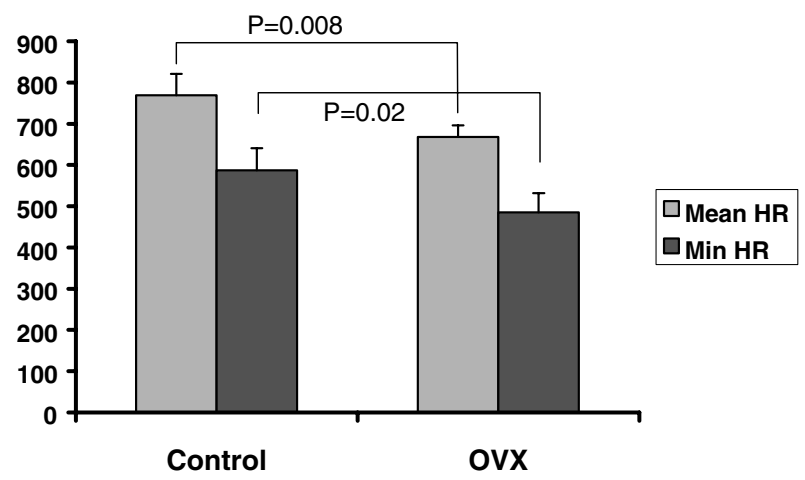

Figure 3. Comparison of the mean and minimum heart rates of ovariectomized versus control mice during 24-hour ambulatory monitoring.

three study groups in any of the measured parameters (Table 1). Throughout the study, the time of ovariectomy did not influence any of the electrophysiologic parameters. Therefore, the PRE and

Table 1. Baseline Surface Electrocardiographic and Electrophysiologic Parameters

\begin{tabular}{|c|c|c|c|c|}
\hline & & Mean & SD & P Value \\
\hline $\mathrm{RR}$ (ms) & $\begin{array}{l}\text { OVX } \\
\text { Control }\end{array}$ & $\begin{array}{l}129 \\
131\end{array}$ & $\begin{array}{r}24 \\
4\end{array}$ & NS \\
\hline PR (ms) & $\begin{array}{l}\text { OVX } \\
\text { Control }\end{array}$ & $\begin{array}{l}39 \\
39\end{array}$ & $\begin{array}{l}4 \\
4\end{array}$ & NS \\
\hline QRS (ms) & $\begin{array}{l}\text { OVX } \\
\text { Control }\end{array}$ & $\begin{array}{l}19 \\
17\end{array}$ & $\begin{array}{l}4 \\
1 \\
2\end{array}$ & NS \\
\hline QT (ms) & $\begin{array}{l}\text { OVX } \\
\text { Control }\end{array}$ & $\begin{array}{l}36 \\
33\end{array}$ & $\begin{array}{l}8 \\
3\end{array}$ & NS \\
\hline $\mathrm{AH}(\mathrm{ms})$ & $\begin{array}{l}\text { OVX } \\
\text { Control }\end{array}$ & $\begin{array}{l}26 \\
26\end{array}$ & $\begin{array}{l}3 \\
2\end{array}$ & NS \\
\hline $\mathrm{HV}$ (ms) & $\begin{array}{l}\text { OVX } \\
\text { Control }\end{array}$ & $\begin{array}{l}11 \\
11\end{array}$ & 1 & NS \\
\hline SNRT (ms) & $\begin{array}{l}\text { OVX } \\
\text { Control }\end{array}$ & $\begin{array}{l}170 \\
157\end{array}$ & $\begin{array}{l}45 \\
25\end{array}$ & NS \\
\hline SNRTc (ms) & $\begin{array}{l}\text { OVX } \\
\text { Control }\end{array}$ & $\begin{array}{l}41 \\
34\end{array}$ & $\begin{array}{l}20 \\
18\end{array}$ & NS \\
\hline AVW (ms) & $\begin{array}{l}\text { OVX } \\
\text { Control }\end{array}$ & $\begin{array}{l}85 \\
83\end{array}$ & $\begin{array}{r}8 \\
10\end{array}$ & NS \\
\hline AV2:1 (ms) & $\begin{array}{l}\text { OVX } \\
\text { Control }\end{array}$ & $\begin{array}{l}64 \\
68\end{array}$ & $\begin{array}{r}6 \\
10\end{array}$ & NS \\
\hline AVERP (ms) & $\begin{array}{l}\text { OVX } \\
\text { Control }\end{array}$ & $\begin{array}{l}58 \\
58\end{array}$ & $\begin{array}{l}7 \\
7\end{array}$ & NS \\
\hline FRP (ms) & $\begin{array}{l}\text { OVX } \\
\text { Control }\end{array}$ & $\begin{array}{l}82 \\
80\end{array}$ & $\begin{array}{l}9 \\
7\end{array}$ & NS \\
\hline VERP (ms) & $\begin{array}{l}\text { OVX } \\
\text { Control }\end{array}$ & $\begin{array}{l}46 \\
33\end{array}$ & $\begin{array}{l}10 \\
10\end{array}$ & NS \\
\hline
\end{tabular}

$\mathrm{SD}=$ standard deviation; OVX = ovariectomized mice; SNRT $=$ sinus node recovery time; SNRTC $=$ sinus node recovery time corrected for the cycle length; AVW = atrioventricular nodal Wenckebach; AV2:1 = atrioventricular nodal 2:1 block; AVERP = atrioventricular nodal effective refractory period; $F R P=$ atrioventricular nodal functional refractory period; $\mathrm{VERP}=$ ventricular effective refractory period. 


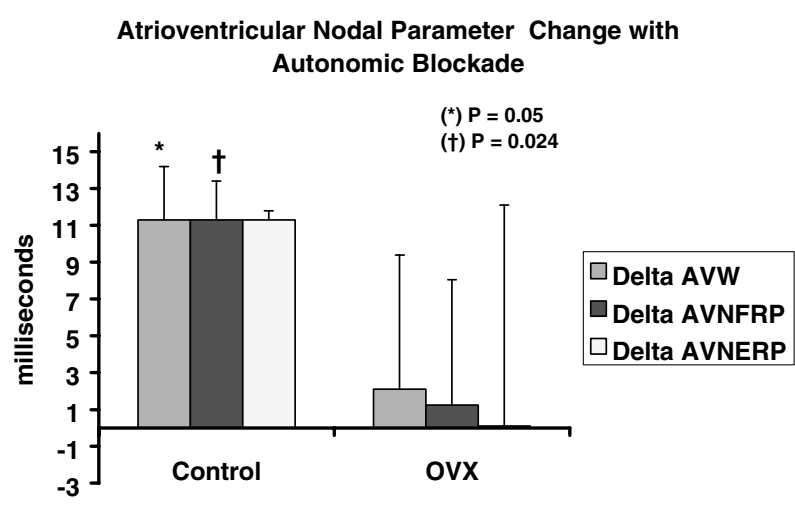

Figure 4. Comparison between ovariectomized and control mice in the degree of change $(\triangle)$ with autonomic blockade in the parameters of atrioventricular nodal Wenckebach periodicity (AVW), atrioventricular nodal effective (ERP), and functional (FRP) refractory periods.

POST groups were treated as one (OVX group) and compared to the Control group. With autonomic blockade, the Control group had a significantly larger change $(\triangle)$ in the atrioventricular $(\mathrm{AV})$ nodal Wenckebach $(\mathrm{AVW})$ periodicity $(\triangle \mathrm{AVW}=11.3 \pm$ 2.9 vs $2.1 \pm 7.3 \mathrm{~ms}, \mathrm{P}=0.05)$ and functional refractory period $(\triangle \mathrm{FRP}=11.3 \pm 2.1$ vs $1.25 \pm 6.8$ $\mathrm{ms}, \mathrm{P}=0.02)$ compared to the ovariectomized mice (Fig. 4). These results were not altered by the time of ovariectomy (PRE vs POST groups). The electrophysiologic parameters obtained postautonomic blockade are shown in Table 2. There were no spontaneous or inducible atrial or ventricular arrhythmias pre- or postautonomic blockade in any of the mice tested.

The weights of the uteri were significantly different among the three groups $(14.3 \pm 6.7 \mathrm{mg}, 23.5 \pm$ $10.6 \mathrm{mg}, 68.5 \pm 17.7 \mathrm{mg}$ for the PRE, POST, and Control groups respectively, $\mathrm{P}<0.001$ for the comparison of the Controls vs PRE and POST, and P < 0.05 for the comparison of PRE vs POST) ((Fig. 5).

\section{DISCUSSION}

The findings of our current study suggest that estrogen modulates the autonomic inputs into the murine sinus and atrioventricular nodes differentially under ambulatory conditions and in the anesthetized state during in vivo electrophysiologic testing. Normal estrogen states seem to increase the sympathetic input to the sinus node under ambulatory conditions whereas low estrogen states seem to decrease the autonomic influence on the murine
Table 2. Postautonomic Blockade Surface Electrocardiographic and Electrophysiologic Parameters

\begin{tabular}{llrrc}
\hline & & Mean & SD & P Value \\
\hline RR (ms) & OVX & 129 & 12 & NS \\
& Control & 137 & 12 & \\
PR (ms) & OVX & 37 & 3 & NS \\
& Control & 38 & 3 & \\
QRS (ms) & OVX & 18 & 1 & NS \\
& Control & 18 & 1 & \\
OT (ms) & OVX & 41 & 10 & NS \\
& Control & 38 & 5 & \\
AH (ms) & OVX & 25 & 3 & NS \\
& Control & 26 & 5 & \\
HV (ms) & OVX & 11 & 1 & NS \\
& Control & 11 & 1 & \\
SNRT (ms) & OVX & 160 & 29 & NS \\
& Control & 181 & 39 & \\
SNRTC (ms) & OVX & 36 & 30 & NS \\
& Control & 33 & 26 & \\
AVW (ms) & OVX & 87 & 8 & NS \\
AVERP (ms) & Control & 90 & 3 & \\
& OVX & 58 & 12 & NS \\
FRP (ms) & Control & 69 & 8 & \\
& OVX & 84 & 7 & NS \\
VERP (ms) & Control & 89 & 6 & \\
& OVX & 46 & 11 & NS \\
& Control & 34 & 10 & \\
& &
\end{tabular}

$\mathrm{SD}=$ standard deviation; OVX = ovariectomized mice; SNRT $=$ sinus node recovery time; SNRTC $=$ sinus node recovery time corrected for the cycle length; AVW = atrioventricular nodal Wenckebach; AV2:1 = atrioventricular nodal 2:1 block; AVERP = atrioventricular nodal effective refractory period; $\mathrm{FRP}=$ atrioventricular nodal functional refractory period; $\mathrm{VERP}=$ ventricular effective refractory period.

atrioventricular node during in vivo electrophysiologic testing. Taken together, these findings, if replicated in humans, might underlie the observed clustering of certain arrhythmias around menstruation $^{21,22}$ and might explain the higher incidence of

\section{Uterus Weight}

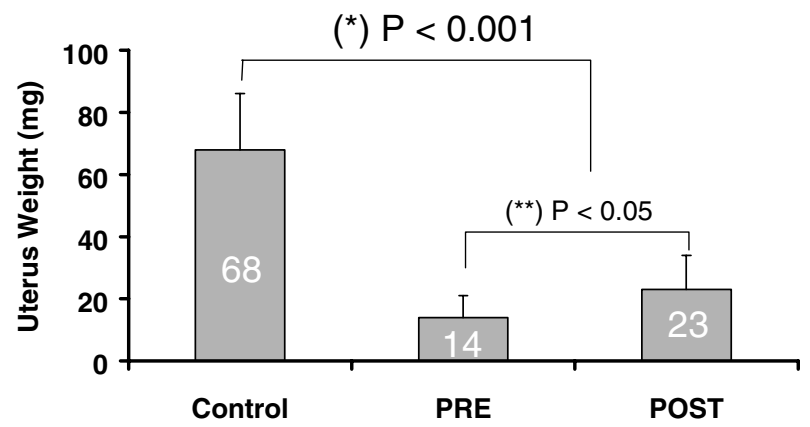

Figure 5. Differences in uteri weight among the three study groups. 
other arrhythmias in men and in postmenopausal women.

According to our data, the time of ovariectomy does not affect the electrophysiology of the murine heart under either condition. Therefore, prior exposure to estrogen does not seem to induce a lasting effect on the cardiac myocytes, particularly on the specialized cells of conduction. After 2 weeks of estrogen deprivation, there is no discernable difference in the heart rate, basic electrophysiologic parameters, or arrhythmia susceptibility in ovariectomized female mice, regardless of the time of ovariectomy.

The mechanism of action of estrogen on the cardiac conduction system of the heart has not been fully elucidated. Numerous theories have been advanced ranging from a direct effect of estrogen on estrogen receptors, which are present throughout the cardiac vasculature and in the myocytes to an indirect effect modulated through the autonomic nervous system.

Using a mouse model of invasive cardiac electrophysiology we had previously shown ${ }^{26}$ that low estrogen states induced by ovariectomy are associated with a shorter atrioventricular nodal conduction time as reflected through the AH interval measured on intracardiac tracings. We had also shown that estrogen replacement therapy given to the mice over a period of 2-3 weeks restores this parameter back to baseline. In our previous work ${ }_{1}^{26}$ we had also shown that in ovariectomized female mice, the right ventricular effective refractory period measured after pretreatment with quinidine is shorter than in intact mice. Again, this parameter normalizes back to baseline with estrogen replacement therapy.

The hypothesis driving our current study focused on the potential role of the timing of ovariectomy (before or after puberty) on the murine cardiac electrophysiology and on its interaction with the autonomic nervous system. Because atrioventricular conduction times and ventricular refractory periods are typically affected by the sympathetic and parasympathetic cardiac inputs, it was normal to test the role of these influences in the mouse and the way in which estrogen modulates them.

At baseline, our current findings did not show any differences in any of the electrophysiologic parameters, including the $\mathrm{AH}$ interval and the ventricular effective refractory period, between the intact Controls and the ovariectomized mice. Although apparently contradicting our previous re- sults ${ }^{26}$ one has to be very careful when extrapolating findings from one study to another, especially when the stain of mice and the anesthesia used are different. The strain of animals has been previously shown to significantly affect the baseline cardiac autonomic status in mice. ${ }^{29}$ The animals used in our current study belonged to the $\mathrm{C} 3 \mathrm{H}$ strain as opposed to the C57/J strain used previously. ${ }^{26}$ Also, the impact of the type of anesthesia used has been well documented by others. ${ }^{30}$ The type of anesthesia used during in vivo electrophysiologic testing in our current study consisted of avertin as opposed to a combination of ketamine and xylazine used in our previous work. ${ }^{26}$ All these differences account for the apparent discrepancy between our current findings and previous publications.

The present study has a number of limitations that deserve to be mentioned. First, it only investigated the effect of estrogen on the cardiac electrophysiologic characteristics in female mice. It did not include male mice or other hormonal manipulations such as progesterone or dihydrotestosterone. Also, it did not include a group of ovariectomized mice in which estrogen levels were restored through estrogen replacement therapy. Applying the same techniques to mice of both sexes with a wider scope of hormonal manipulations is being considered for future studies. Second, in our current study we did not measure plasma estrogen levels in the various study groups. We had previously shown, however, that the weight of uteri is a valid surrogate for this hormonal level. Finally, the degree of extrapolation of results from the mouse to humans is always limited by considerations of size, rate, and interspecies differences. Discrepancies between humans and mice in the types of dominant ionic channels have been reported. For example ${ }^{31}$ repolarization in the mouse is primarily dependent on the outward transient current $\left(I_{\mathrm{to}}\right)$, unlike in humans where the inward rectifier potassium rapid $\left(I_{\mathrm{kr}}\right)$ and slow $\left(I_{\mathrm{ks}}\right)$ currents are the dominant ones involved.

Though the underlying molecular mechanisms responsible for the current observations are not fully characterized, the current study represents a step forward toward defining the role of gonadal hormones on cardiac electrophysiology in normal wild-type mice. This study suggests a significant role for the autonomic nervous system as one of potentially numerous mechanistic pathways. Future applications of this model under various designs and conditions, as well as in transgenic mouse 
models may translate into a better understanding of the pathophysiology of cardiac arrhythmias and ultimately into new therapeutic options.

\section{REFERENCES}

1. Wellens HJJ. The electrophysiologic properties of the accessory pathway in the Wolf-Parkinson-White-White syndrome. In Wellens HJJ, Lie KI, Janse MJ, (eds.): The Conduction System of the Heart. Leiden, the Netherlands, HE Stenfert Kroese B.V., 1976, pp. 567-588.

2. Wellens HJJ, Bar FW, Farre J, et al. Diagnosis and incidence of concealed accessory pathway in patients suffering from paroxysmal AV junctional tachycardias. Rev Lat Cardiol 1980;1:60-67.

3. Rodriguez LM, de Chillou C, Schlapfer J, et al. Age at onset and gender of patients with different types of supraventricular tachycardias. Am J Cardiol 1992;70:1213-1215.

4. Larsen JA, Kadish AH. Effects of gender on cardiac arrhythmias. J Cardiovasc Electrophysiol 1998;9:655-664.

5. The National Heart Lung and Blood Institute Working Group on Atrial Fibrillation. Atrial fibrillation: Current understandings and research imperatives. J Am Coll Cardiol 1993;22:1830.

6. Bazett HC. An analysis of the time relationship of electrocardiograms. Heart 1920;7:353-370.

7. Burke JH, Ehlert FA, Kruse JT, et al. Gender-specific differences in the QT interval and the effects of the autonomic tone and menstrual cycle in healthy adults. Am J Cardiol 1997;79:178-181.

8. Lehmann $\mathrm{MH}$, Hardy S, Archibald D, et al. JTc prolongation with d,1-sotalol in women versus men. Am J Cardiol 1999;83:354-359.

9. Ebert SN, Liu XK, Woosley RL. Female gender as a risk factor for drug-induced cardiac arrhythmias: Evaluation of clinical and experimental evidence. J Women Health 1998;7:547-557.

10. Tanaka H, Sekine $T$, Nishimaru $K$, et al. Role of sarcoplasmic reticulum in myocardial contraction of neonatal and adult mice. Comp Biochem Physiol 1998;120:431-438.

11. Katsube Y, Yokoshiki H, Nguyen L, et al. L-type $\mathrm{Ca}^{2+}$ currents in ventricular myocytes from neonatal and adult rats. Can J Physiol Pharm 1998;76:873-881.

12. Leblanc N, Chartier D, Gosselin $\mathrm{H}$, et al. Age and gender differences in the excitation-contraction coupling of the rat ventricle. J Physiol 1998;511:533-548.

13. Rahimian $R$, Wang $X$, van Breeman C. Gender differences in the basal intracellular $\mathrm{Ca}^{2 \pm}$ concentration in rat valvular endothelial cells. Biochem Biophys Res Comm 1998;248:916919.

14. Chandler MP, DiCarlo SE. Acute exercise and gender alter cardiac autonomic tonus differently in hypertensive and normotensive rats. Am J Physiol 1998;274:R510-R516.

15. Snyder DL, Gayheart-Walsten PA, Rhie S, et al. Effect of age, gender, rat strain, and dietary restriction, on nore- pinephrine release from cardiac synaptosomes. J Gerontol 1998;53:B33-B41.

16. Airaksinen $\mathrm{KE}$, Ikaheimo $\mathrm{MJ}$, Linnaluoto $\mathrm{M}$, et al. Gender differences in autonomic and hemodynamic reactions to abrupt coronary occlusion. J Am Coll Cardiol 1998;31:301306.

17. Gregoire J, Tuck S, Yamamoto Y, et al. Heart rate variability at rest and exercise: Influence of age, gender, and physical training. Can J Appl Physiol 1996;21:445-470.

18. Umetani K, Singer DH, McCraty R, et al. Twenty-four hour time domain heart rate variability and heart rate: Relations to age and gender over nine decades. J Am Coll Cardiol 1998;31:593-601.

19. Hara M, Danilo P Jr, Rosen MR. Effects of gonadal steroids on ventricular repolarization and on the response to E4031. J Pharmacol Exp Ther 1998;285:1068-1072.

20. Rosano GMC, Leonardo F, Dicandia C, et al. Acute electrophysiologic effect of estradiol $17 \beta$ in menopausal women. Am J Cardiol 2000;86:1385-1387.

21. Rosano GM, Leonardo F, Sarrel PM, et al. Cyclical variation in paroxysmal supraventricular tachycardia in women. Lancet 1996;347:786-788.

22. Myeburg RJ, Cox MM, Interian A Jr, et al. Cycling of inducibility of paroxysmal supraventricular tachycardia in women and its implications for timing of electrophysiologic procedures. Am J Cardiol 1999;83(7):1049-1054.

23. McHugh NA, Merrill GF, Powell SR. Estrogen diminishes post-ischemic hydroxyl radical production. Am J Physiol 1998;274:H1950-H1954.

24. Node K, Kitakaze M, Kosaka $\mathrm{H}$, et al. Amelioration of ischemia- and reperfusion-induced myocardial injury by 17beta-estradiol: Role of nitric oxide and calcium-activated potassium channels. Circulation 1997;96:1953-1963.

25. Kim YD, Chen B, Beauregard J, et al. 17 beta-estradiol prevents dysfunction of canine coronary endothelium and myocardium and reperfusion arrhythmias after brief is chemia/reperfusion. Circulation 1996;94:2901-2908.

26. Saba S, Zhu W, Aronovitz MJ, et al. Effects of estrogen on cardiac electrophysiology in female mice. J Cardiovasc Electrophysiol 2002; 13:276-280.

27. Saba S, Wang PJ, Homoud M, et al. Invasive cardiac electrophysiologic observations in the mouse model. Giornale Italiano di Aritmologia e Cardiostimolazione 2002;5:148-153.

28. Saba S, London B, Ganz LI. Autonomic blockade unmasks maturational differences in rate dependent atrioventricular nodal conduction and facilitation in the mouse. J Cardiovasc Electrophysiol 2003;14:191-195.

29. Shusterman V, Usiene I, Harrigal C, et al. Strain-specific patterns of autonomic nervous system activity and heart failure susceptibility in mice. Am J Physiol Heart Circ Physiol 2002;282:H2076-H2083.

30. Roth DM, Swaney JS, Dalton ND, et al. Impact of anesthesia on cardiac function during echocardiography in mice. Am J Physiol Heart Circ Physiol 2002;282:H2134-H2140.

31. London B, Wang DW, Hill JA, et al. The transient outward current in mice lacking the potassium channel gene Kv1.4. J Physiol 1998;509:171-182. 